\title{
Automutilação e seus fatores determinantes: Uma revisão integrativa
}

\author{
Self-mutilation and its determinants factors: An integrative review \\ La automutilación y sus determinantes: Una revisión integradora
}

Recebido: 12/07/2021 | Revisado: 18/07/2021 | Aceito: 23/07/2021 | Publicado: 31/07/2021

\author{
Danyela dos Santos Lima \\ ORCID: https://orcid.org/0000-0003-4677-5656 \\ Universidade Estadual Vale do Acaraú, Brasil \\ E-mail: dany_uruoca@hotmail.com \\ Eliany Nazaré Oliveira \\ ORCID: https://orcid.org/0000-0002-6408-7243 \\ Universidade Estadual Vale do Acaraú. Brasil \\ E-mail: elianyy@gmail.com \\ Sabrina da Silva França \\ ORCID: https://orcid.org/0000-0003-1018-0159 \\ Universidade Estadual Vale do Acaraú, Brasil \\ E-mail:sabrinafranca480@gamil.com \\ Natasha Vasconcelos Sobrinho \\ ORCID: https://orcid.org/0000-0003-3605-8602 \\ Universidade Estadual Vale do Acaraú. Brasil \\ E-mail: Natashavascon2206@hotmail.com \\ Ludmilla Alves Santos \\ ORCID: https://orcid.org/0000-0003-4592-527X \\ Prefeitura Municipal de Forquilha. Brasil \\ E-mail: ludmillaalves91@hotmail.com \\ Flávio Araújo Prado \\ ORCID: https://orcid.org/0000-0002-8310-2330 \\ Prefeitura Municipal de Forquilha. Brasil \\ E-mail: sesa.forquilha@gmail.com
}

\begin{abstract}
Resumo
O objetivo deste estudo foi analisar, na literatura científica nacional e internacional, o que tem sido produzido sobre fatores determinantes da automutilação. Realizou-se uma revisão integrativa a partir da seguinte questão norteadora: Quais evidências científicas estão sendo publicadas sobre a automutilação e seus fatores de risco? A busca ocorreu em quatro bases de dados e abrangeu artigos com texto completo disponível, publicados entre 2016 e 2021, nos idiomas português, inglês e espanhol. A partir da amostra de 16 artigos, obteve-se com os resultados: fatores de adversidade familiar, acontecimentos adversos na infância, o contágio social da internet e o diagnóstico prévio de transtorno mental como importantes determinantes da automutilação nas diversas etapas da vida. Conclui-se que por se tratar de um problema de origem multifatorial, necessita de intervenções intersetoriais que proporcionem um cuidar holístico e de clínica ampliada. Portanto, sendo já considerado um problema de Saúde Pública nacional e internacional, é necessário a construção de Políticas Públicas que contenham o crescimento do número de casos e promovam a prevenção das diversas formas de violência autoprovocada.
\end{abstract}

Palavras-chave: Automutilação; Fatores de risco; Revisão; Saúde mental.

\begin{abstract}
The aim of this study was to analyze what has been produced in the national and international scientific literature about determinants factors of self-mutilation. An integrative review was carried out based on the following guiding question: What scientific evidence is being published about self-mutilation and its risk factors? The search took place in four databases and covered articles with available full text, published between 2016 and 2021, in Portuguese, English and Spanish. From the sample of 16 articles, the following results were obtained: family adversity factors, adverse events in childhood, social influence mediated by the internet and previous diagnosis of mental disorder are important determinants factors of self-mutilation in different stages of life. It is concluded that because self-mutilation is a problem of multifactorial origin, it requires intersectoral interventions, holistic care, and amplified clinic. Therefore, as self-mutilation is considered a national and international public health problem, it is necessary to build public policies that contain the growth in the number of cases and promote the prevention of the various forms of this type of violence.
\end{abstract}

Keywords: Self Mutilation; Risk factors; Revision; Mental health.

\section{Resumen}

El objetivo de este estudio fue analizar lo producido en la literatura científica nacional e internacional sobre los determinantes de la automutilación. Se realizó una revisión integradora basada en la siguiente pregunta orientadora: 
¿Qué evidencia científica se está publicando sobre la automutilación y sus factores de riesgo? La búsqueda se realizó en cuatro bases de datos y cubrió artículos con texto completo disponible, publicados entre 2016 y 2021, en portugués, inglés y español. De la muestra de 16 artículos se obtuvieron los siguientes resultados: factores de adversidad familiar, eventos adversos en la infancia, influencia social mediada por internet y diagnóstico previo de trastorno mental son importantes determinantes de automutilación en diferentes etapas de la vida. Se concluye que la automutilación es un problema de origen multifactorial que requiere intervenciones intersectoriales, atención integral y clínica ampliada. Por tanto, al ser considerada la automutilación un problema de salud pública nacional e internacional, es necesario construir políticas públicas que contengan el crecimiento del número de casos y promuevan la prevención de las diversas formas de este tipo de violencia.

Palabras-clave: Automutilación; Factores de riesgo; Revisión; Salud mental.

\section{Introdução}

A automutilação consiste em comportamentos autolesivos deliberados, repetitivos e intencionais em busca do alívio a uma dor psíquica intensa ou até mesmo como forma punitiva. Comumente incluem comportamentos como cortes, arranhões, batidas e/ou queimaduras na pele, esmagamento das mãos ou dos pés contra a parede ou objetos, raspagem da pele, batidas em si mesmo, entre outros (Peh et al., 2017).

Desse modo, automutilação é descrita como um fenômeno complexo, que apresenta variações quanto à nomenclatura, ao conceito, à prevalência, à origem e a determinantes. Atualmente, os estudos sobre este comportamento se dividem em dois grupos, que se distinguem em relação a intenção do ato, sendo eles: Deliberate self harm, que inclui todos os métodos de automutilação, não diferenciando se é uma tentativa de suicídio ou não e Non Suicidal Self Injury (NSSI), que diz respeito a lesões como cortes, queimaduras e arranhões, referindo-se somente à destruição do tecido na ausência da intenção de morte. Ademais, sabemos que vários fatores emocionais, contextuais e sociais podem levar a comportamentos prejudiciais à saúde como a automutilação. Este comportamento, apesar de ocorrer em diversas faixas etárias, é mais comum em adolescentes com início entre os 13 e 14 anos, podendo perdurar por 10 ou mais anos (Moraes et al., 2020).

Embora os comportamentos de automutilação sejam em grande parte não fatais, os indivíduos que se envolvem em automutilação podem sofrer lesões que requerem atenção médica e também apresentam maior risco de suicídio (Peh et al., 2017; Moraes et al., 2020). Em um estudo realizado nos Estados Unidos, evidenciou-se que após a automutilação não fatal, o público estudado apresentava risco 26,7 vezes maior de suicídio do que a população geral (Olfson et al., 2018). Ressalta-se a importância dos cuidados de acompanhamento para ajudar a garantir a segurança desse público.

No mesmo sentido, estudos nacionais e internacionais abordam os motivos que levam o indivíduo a se automutilar. Dentre as causas mais comuns estão a tentativa de modular as reações emocionais que são intensas e comuns na adolescência, a baixa capacidade de resolver problemas, a dificuldade de comunicação, a tolerância baixa ao estresse e a sensibilidade aumentada a emoções negativas, visto que se busca uma forma para lidar com essas situações. Nisso, o sofrimento e a solidão são gatilhos para a automutilação (Gorodetsky et al., 2016; Richmond-Rakerd et al., 2019). Alguns estudos caracterizam a automutilação predominantemente como função automática negativa, responsabilizando-a pela regulação de emoções não desejadas e não a caracterizando como um ato ou comportamento manipulador (Moreira et al., 2021).

Diante do contexto da automutilação como um problema de Saúde Pública a nível global e considerando os impactos resultantes desta prática na vida presente e futura dos indivíduos que a praticam, o atual estudo se propôs a contribuir com informações acerca da automutilação, tendo em vista a relevância da temática no cenário atual bem como a carência de literatura sobre o assunto tão necessária para intervenções que visem redução dos riscos e das vulnerabilidades aos comportamentos autolesivos.

Segundo a Organização Mundial de Saúde, Determinantes sociais de saúde são definidos como condições sociais, econômicas, políticas, culturais, e ambientais nas quais as pessoas estão inseridas e que podem influenciar diretamente ou indiretamente no seu estado de saúde (OMS, 2011). 
Desse modo, objetivou-se analisar na literatura científica nacional e internacional o que tem sido produzido sobre fatores determinantes da automutilação, tendo como questão norteadora: Quais evidências científicas estão sendo publicadas sobre a automutilação e seus fatores determinantes?

\section{Metodologia}

Trata-se de uma revisão integrativa da literatura, desenvolvida a partir das seguintes etapas: identificação da temática do estudo e elaboração da pergunta norteadora; busca de artigos nas bases de dados; análise crítico-reflexiva dos estudos encontrados; interpretação e apresentação dos resultados e síntese final da revisão (Souza et al., 2010).

Assim, a questão norteadora do estudo, com base na estratégia PICo (População, Interesse e Contexto) (Lockwood et al., 2019) foi: Quais evidências científicas estão sendo publicadas sobre a automutilação e seus fatores determinantes? Para a qual se consideraram: $\mathrm{P}=$ população geral; $\mathrm{I}=$ fatores de risco/fatores determinantes e $\mathrm{Co}=$ automutilação.

A busca ocorreu nas bases de dados: Scopus; National Library of Medicine and National Institutes of Health (PubMed/MEDLINE); Science Direct (Elsevier); e Biblioteca Virtual em Saúde; BVS (BIREME). Para a busca, foram usados Descritores em Ciências da Saúde - DeCS e Medical Subject Headings - MeSH por meio dos cruzamentos: "Self -harm AND risk factors", "Self-harm AND causer agente", "Self-injury AND causer agente" e "Self-injury AND risk factors". Para corroborar a exaustão da possibilidade de busca, o acesso ocorreu a partir do portal de periódicos da Coordenação de Aperfeiçoamento de Pessoal de Nível Superior (CAPES) em cobertura de Internet Protocol (IP) pertencente à Universidade Estadual Vale do Acaraú.

Nesse sentido, os critérios de inclusão foram: artigos disponíveis na íntegra sobre fatores de risco ou fatores determinantes da automutilação, publicados dentro do período de 2016 - 2021, nos idiomas: português, inglês e espanhol. Excluíram-se os artigos que não possuíssem relação com a questão de pesquisa, os que não apresentavam disponíveis completamente e artigos duplicados.

A partir da busca, foram identificados inicialmente um total de 3225 publicações com qual procedeu-se à leitura dos títulos e resumos dos artigos, sendo nessa etapa excluídas 3169 por não atenderem aos critérios de inclusão e 11 foram excluídas por serem repetidas. Posteriormente, realizou-se a análise completa de 45 artigos através instrumento semiestruturado, que possibilitou a identificação de informações dos estudos como título, autores, ano, país, características metodológicas e principais resultados. Finalmente, os estudos foram classificados em níveis de evidências, conforme proposto por Galvão (2006) e selecionadas 16 artigos com maiores níveis de evidência. 
Figura 1. Fluxograma com a apresentação da seleção dos artigos.

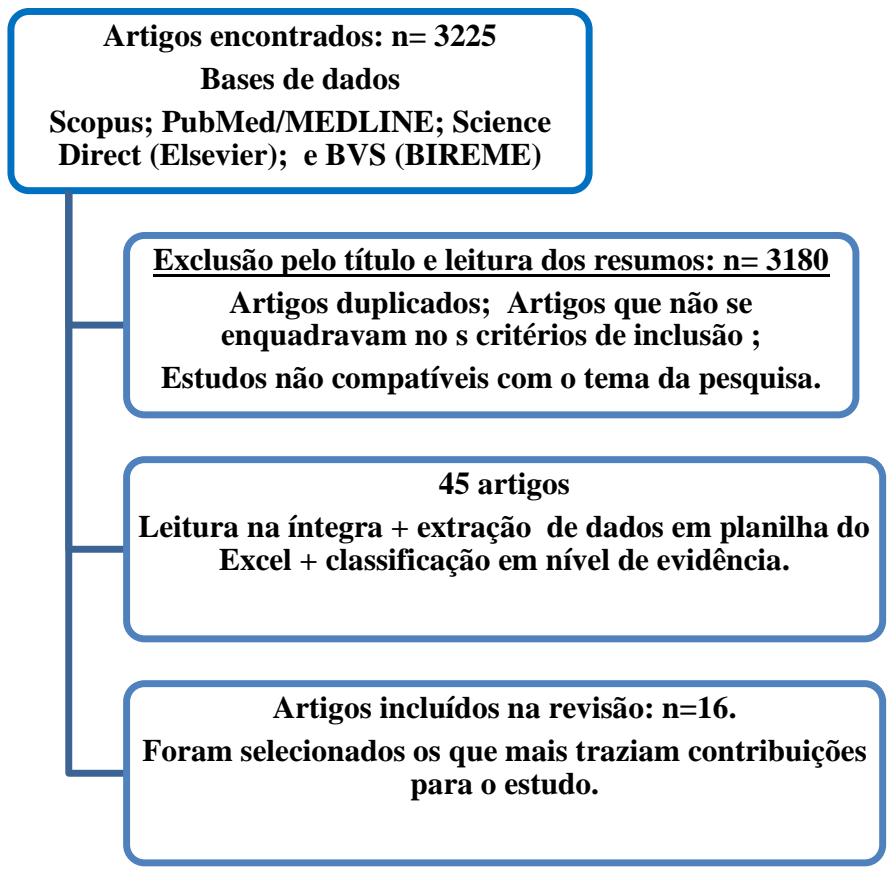

Fonte: Autores.

Destaca-se que a busca e a seleção dos artigos foram realizadas por três pesquisadores independentes com o intuito de verificar possíveis divergências nos achados. O estudo respeitou os princípios éticos e legais da Resolução 510/2016 do Conselho Nacional de Saúde que envolvem pesquisas com informações de domínio público.

\section{Resultados e Discussão}

Quanto ao nível de evidência, foram incluídos dois artigos de nível I (revisão sistemática ou metanálise de múltiplos estudos controlados ou diretrizes clínicas com revisão sistemática), um estudo de nível II (ensaio clínico randomizado), oito estudos de nível IV (coortes e estudos de caso-controle bem delineados), três estudos de nível V (revisão sistemática de estudos descritivos e qualitativos) e dois estudos de nível VI (descritivos ou qualitativos). Em relação à distribuição geográfica, o Reino Unido liderou as publicações, com cinco estudos, seguido de Estados Unidos com três produções e China com duas. As demais produções representaram unitariamente Austrália, Brasil, Cingapura, Itália e Taiwan. Essa variação nos locais de publicação torna possível uma visão mais ampla sobre os fatores determinantes.

Quadro 1. Principais informações sobre artigos publicados entre 2016- 2021 sobre fatores determinantes da automutilação.

\begin{tabular}{|l|l|l|l|l|}
\hline \multicolumn{1}{|c|}{$\begin{array}{c}\text { Procedência/ } \\
\text { Periódico }\end{array}$} & \multicolumn{1}{|c|}{$\begin{array}{c}\text { Local do estudo/ } \\
\text { Idioma }\end{array}$} & \multicolumn{1}{c|}{ Título } & \multicolumn{1}{c|}{$\begin{array}{c}\text { Nível de } \\
\text { Evidência }\end{array}$} \\
\hline $\begin{array}{l}\text { BIREME/ } \\
\text { The Lancet } \\
\text { Psychiatry. }\end{array}$ & $\begin{array}{l}\text { Inglaterra/ } \\
\text { Inglês }\end{array}$ & $\begin{array}{l}\text { Risk factors for self-harm in prison: a } \\
\text { systematic review and meta-analysis. }\end{array}$ & Favril, et al. / 2020. & Nível I \\
\hline $\begin{array}{l}\text { Scopus/ } \\
\text { Journal of Medical } \\
\text { Internet Research } \\
\text { Publications. }\end{array}$ & $\begin{array}{l}\text { Estados Unidos/ } \\
\text { Inglês }\end{array}$ & $\begin{array}{l}\text { Examining the effects of self-harm and } \\
\text { contagion of the blue whale's suicide } \\
\text { challenge on YouTube and Twitter: a } \\
\text { qualitative study. }\end{array}$ & $\begin{array}{l}\text { Khasawneh, et al./ } \\
2020 .\end{array}$ & Nível IV \\
\hline
\end{tabular}


Research, Society and Development, v. 10, n. 9, e45510918155, 2021

(CC BY 4.0) | ISSN 2525-3409 | DOI: http://dx.doi.org/10.33448/rsd-v10i9.18155

\begin{tabular}{|c|c|c|c|c|}
\hline $\begin{array}{l}\text { Science Direct/ } \\
\text { Child Abuse \& } \\
\text { Neglect. }\end{array}$ & Cingapura/ Inglês & $\begin{array}{l}\text { Neglect Emotion dysregulation as a } \\
\text { mechanism linking childmaltreatment } \\
\text { exposure and self-harm behaviors } \\
\text { inadolescents. }\end{array}$ & Peh, et al./ 2017. & Nível V \\
\hline $\begin{array}{l}\text { Scopus/ } \\
\text { Genes, Brain and } \\
\text { Behavior. }\end{array}$ & Itália/ Inglês & $\begin{array}{l}\text { Predictors for self-directed aggression } \\
\text { in Italian prisoners include } \\
\text { externalizing behaviors, childhood } \\
\text { trauma and the serotonin transporter } \\
\text { gene polymorphism 5-HTTLPR. }\end{array}$ & $\begin{array}{l}\text { Gorodetsky, et al./ } \\
2016 .\end{array}$ & Nível V \\
\hline $\begin{array}{l}\text { MEDLINE/ } \\
\text { American Journal of } \\
\text { Psychiatry }\end{array}$ & Reino Unido/Inglês & $\begin{array}{l}\text { Adolescents Who Self-Harm and } \\
\text { Commit Violent Crime: Testing Early- } \\
\text { Life Predictors of Dual Harm in a } \\
\text { longitudinal Cohort Study. }\end{array}$ & $\begin{array}{l}\text { Richmond-Rakerd, } \\
\text { et al./ } 2019 .\end{array}$ & Nível IV \\
\hline $\begin{array}{l}\text { MEDLINE/ } \\
\text { BMC Psychiatry. }\end{array}$ & $\begin{array}{l}\text { Reino Unido/ } \\
\text { Inglês }\end{array}$ & $\begin{array}{l}\text { Feasibility of a randomised controlled } \\
\text { trial of remotely delivered problem- } \\
\text { solving cognitive behaviour therapy } \\
\text { versus usual care for young people with } \\
\text { depression and repeat self-harm: } \\
\text { lessons learnt (e-DASH). }\end{array}$ & Sayal, et al./ 2019. & Nível II \\
\hline $\begin{array}{l}\text { MEDLINE/ } \\
\text { Revista Brasileira de } \\
\text { Enfermagem. }\end{array}$ & Brasil/ Português & $\begin{array}{l}\text { "Caneta é a lâmina, minha pele o } \\
\text { papel”: fatores de risco da } \\
\text { automutilação em adolescentes. }\end{array}$ & Moraes, et al./ 2020. & Nível IV \\
\hline $\begin{array}{l}\text { PUBMED/ } \\
\text { Journal of Pediatric } \\
\text { and Adolescent } \\
\text { Gynecology. }\end{array}$ & China/ Inglês & $\begin{array}{l}\text { A 6-year Longitudinal Study of Self- } \\
\text { harm and Suicidal Behaviors among } \\
\text { Chinese Adolescents in Hong Kong. }\end{array}$ & $\begin{array}{l}\text { Law \& } \\
\text { Shek/ } 2016 .\end{array}$ & Nível IV \\
\hline $\begin{array}{l}\text { MEDLINE/ } \\
\text { The Journal of } \\
\text { Pediatric. }\end{array}$ & $\begin{array}{l}\text { Estados Unidos/ } \\
\text { Inglês }\end{array}$ & $\begin{array}{l}\text { Suicide After Deliberate Self-Harmin } \\
\text { Adolescents and Young Adults. }\end{array}$ & Olfson, et al./ 2018. & Nível IV \\
\hline $\begin{array}{l}\text { SCIENCE DIRECT/ } \\
\text { PSIQUIATR } \\
\text { IA } \\
\text { EUROPEIA. }\end{array}$ & Austrália/ Inglês & $\begin{array}{l}\text { Predicting the incidence of non-suicidal } \\
\text { self-injury in college students. }\end{array}$ & $\begin{array}{l}\text { Kiekens, et al./ } \\
2019 .\end{array}$ & Nível VI \\
\hline $\begin{array}{l}\text { MEDLINE/ } \\
\text { Women's Health } \\
\text { Issues. }\end{array}$ & $\begin{array}{l}\text { Estados Unidos/ } \\
\text { Inglês }\end{array}$ & $\begin{array}{l}\text { Gender Differences in Suicide and Self- } \\
\text { Directed Violence Risk Among } \\
\text { Veterans With Post-traumatic Stress } \\
\text { and Substance Use Disorders. }\end{array}$ & $\begin{array}{l}\text { Ronzitti, et al./ } \\
2019 .\end{array}$ & Nível VI. \\
\hline $\begin{array}{l}\text { BIREME/ PLOS } \\
\text { ONE. }\end{array}$ & Taiwan/ Inglês & $\begin{array}{l}\text { Relationships between Internet use, } \\
\text { deliberate self-mutilation and happiness } \\
\text { in adolescents: a pilot study of birth } \\
\text { cohort in Taiwan. }\end{array}$ & $\begin{array}{l}\text { Lung, et al./ } \\
2020 .\end{array}$ & Nível IV \\
\hline $\begin{array}{l}\text { MEDLINE/ } \\
\text { International Journal } \\
\text { of Environmental } \\
\text { Research and Public } \\
\text { Health. }\end{array}$ & China /Inglês & $\begin{array}{l}\text { Prospective interpersonal and } \\
\text { intrapersonal predictors of initiation and } \\
\text { cessation of non-suicidal self-harm } \\
\text { among Chinese adolescents. }\end{array}$ & Wang, et al./ 2020. & Nível IV \\
\hline
\end{tabular}




\begin{tabular}{|l|l|l|l|l|}
\hline $\begin{array}{l}\text { BIREME/ } \\
\text { Epidemiology and } \\
\text { Psychiatric Sciences. }\end{array}$ & Reino Unido/ Inglês & $\begin{array}{l}\text { Spatial patterning and correlates of self- } \\
\text { harm in Manchester, England. }\end{array}$ & Lin, et al./ 2019. & Nível V \\
\hline $\begin{array}{l}\text { BIREME/ } \\
\text { European Child \& } \\
\begin{array}{l}\text { Adolescent } \\
\text { Psychiatry. }\end{array}\end{array}$ & $\begin{array}{l}\text { Reino Unido/ } \\
\text { Inglês }\end{array}$ & $\begin{array}{l}\text { School absenteeism as a risk factor for } \\
\text { self-mutilation and suicidal ideation in } \\
\text { children and adolescents: a systematic } \\
\text { review and meta-analysis. }\end{array}$ & Epstein, et al./ 2020. & Nível I \\
\hline $\begin{array}{l}\text { MEDLINE/ } \\
\text { Journal of Neurology }\end{array}$ & $\begin{array}{l}\text { Reino Unido/ } \\
2018\end{array}$ & $\begin{array}{l}\text { Risk factors for self-harm in people } \\
\text { with epilepsy. }\end{array}$ & Gorton, et al./ 2018 & Nível IV. \\
\hline
\end{tabular}

Quadro produzido pelos autores. A classificação de nível de evidência foi baseada em Galvão (2006). Fonte: Autores.

No que se refere aos fatores determinantes para automutilação, optamos apresentá-los mediante categorias para facilitar a compreensão:

\subsection{Fatores de adversidade familiar e acontecimentos adversos na infância}

Identificou-se que fatores familiares associados a experiências relacionais traumáticas apresentam muita influência no contexto da automutilação. Com base nos resultados dos estudos disponíveis, pode-se argumentar que antecedentes de conflitos familiares, quebra de vínculos como divórcio dos pais ou morte de um deles, crítica excessiva dos pais, falta de apoio familiar, problema do álcool na família, violência doméstica, brigas interpessoais e viver em famílias extensas são fatores de risco para violência autoprovocada. (Law \& Shek, 2016; Moraes et al., 2020).

Isso se confirma através de outros estudos os quais afirmam que a automutilação apresenta como principais fatores associados, além de problemas de saúde física, eventos negativos na vida, status econômico familiar ruim, alto nível de educação dos pais, divorciados ou pais viúvos e história familiar de suicídio. Todas essas características foram significativamente associadas a violência autoprovocada. Esse mesmo estudo, realizado com adolescentes, apresentou resultados interessantes ao concluir que um em cada quatro adolescentes chineses relata ter se envolvido com automutilação e 3,8\% tentaram suicídio (Liu et al., 2017).

A automutilação funciona como uma estratégia compensatória para lidar e regular emoções angustiantes que podem resultar da exposição precoce a ambientes e situações adversas. Consonante com essa visão, muitos estudos mostram associação entre automutilação e alguns acontecimentos na vida e na infância como: abuso sexual infantil, abuso físico, negligência, bullying e até mesmo desvantagem econômica (Richmond-Rakerd et al., 2019; Gorodetsky et al., 2016; Law \& Shek, 2016). Percebe-se também que a exposição cumulativa a essas experiências adversas está relacionada a um aumento de dose-resposta no risco de automutilação do adolescente e outros comportamentos de risco na fase adulta. A exposição precoce a ambientes violentos, abusivos e/ou negligentes pode interromper o desenvolvimento de habilidades de regulação de emoções saudáveis e competências socioemocionais. Mediante isso, identificou-se que desregulação emocional media a associação entre a gravidade da exposição a maus tratos e à frequência de automutilação (Peh et al., 2017).

Um estudo de coorte realizado na Inglaterra (Richmond-Rakerd et al., 2019), mostrou que crianças entre 6 e 16 anos que eram frequentemente agredidas fisicamente, por bullying, na escola, tinham um maior risco de cometer automutilação e cometerem crimes violentos quando adultos. Outro estudo realizado com prisioneiros caucasianos italianos, do sexo masculino, mostrou que certos comportamentos violentos previam fortemente a agressão autodirigida e continham grande influência de sentimentos internalizados como sintomas depressivos, sendo que o trauma infantil se mostrou como fator de risco predominante (Gorodetsky et al., 2016). 


\subsection{Internet e o contágio social}

Estudos apontaram que o uso de mídia social pode ser um fator contribuinte para o aumento significativo nas taxas de automutilação e de sintomas depressivos, principalmente entre adolescentes, na última década. Indivíduos vulneráveis mentalmente correm um risco maior de perceber o comportamento autolesivo como uma estratégia de enfrentamento eficaz, particularmente quando eles veem outros usarem esses comportamentos para alcançar um objetivo. Por meio do contágio social, esses comportamentos prejudiciais podem se difundirem rapidamente através da exposição repetitiva e modelagem via mídia social, especialmente quando esse tipo de conteúdo se torna viral. Um exemplo bem significativo da automutilação e do suicídio nas redes social foram jogos como o "Jogo da Baleia Azul". No jogo, o sujeito era desafiado a cometer atos de automutilação e a publicar para os demais participantes. Uma vez dentro do jogo, era proibida a desistência e a última fase do jogo era o suicídio (Khasawneh et al., 2020).

Em Taiwan, estudos que buscaram fazer relações entre o vício da Internet e automutilação deliberada entre adolescentes identificaram que os sujeitos que passaram mais de cinco horas online durante os dias de folga da escola apresentaram maior risco de automutilação relacionada Cyberbullying e mostraram um nível mais baixo de felicidade e autoestima (Lung et al., 2020).

Outros estudos corroboram com essa ideia ao afirmarem que a adolescência contemporânea é marcada pela "solidão afetiva”, em que a ausência dos pais é preenchida por aparelhos eletrônicos. Dessa forma, seus referenciais passam a ser personalidades impessoais e virtuais. Logo, a identificação com seus pares em mídias sociais acaba por influenciar bastante suas ações, pois a adesão a determinados comportamentos o permite se assemelhar a grupos de pertencimento e serem mais rapidamente aceitos (Silva \& Botti, 2018).

As redes sociais possuem, na atualidade, uma configuração de interação social entre os adolescentes e a exposição possibilita contágios e disseminação de tais comportamentos. As imagens de automutilação são postadas repetidamente mostrando ferimentos, com lesões leves ou moderadas e exposição de como fazê-las (Brown et al., 2017).

Almeida et al. (2018) também aponta que a dependência da internet, o bullying e cyberbullying influenciam de automutilação bem como de depressão e suicídio. No entanto, não existem estatísticas que reforcem esta afirmação diante da condição de comportamentos secretos e ainda poucos estudos científicos referentes ao tema. Esse afirma que adolescentes com familiares ou colegas que praticam esse tipo de ação contra si têm maior chance de repetir tal comportamento e as mídias sociais tratam de potencializar e espalhar esta tendência.

A Internet apresenta um impacto potencial no desenvolvimento de comportamento autolesivo não suicida e no suicídio. Nesse contexto, pode surgir como ambiente de risco, pois colabora com a efetivação do comportamento como também pode ser usado como estratégia contemporânea de prevenção. Atualmente a Internet faz parte do cotidiano de milhares de pessoas em todo o mundo, com características como atemporalidade e extraterritorialidade cada vez mais adeptos (Silva \& Botti, 2018).

\subsection{Diagnóstico prévio de transtorno mental}

A automutilação é considerada uma manifestação de sofrimento psíquico que pode estar associado a alguns transtornos mentais. Diante disso, o diagnostico prévio de transtornos mentais foi apontado como um fator preditivo. Identificou-se que transtornos por uso de substâncias, transtornos de personalidade, esquizofrenia, psicoses, transtornos de personalidade/ansiedade e transtornos depressivos aumentaram o risco geral de automutilação, independentemente do sexo. Destaca-se o aumento dos riscos de automutilação de acordo com o aumento do número de transtornos mentais e o aumento do risco de morte por suicídio em transtornos psicóticos (Olfson et al., 2018; Ronzitti et al., 2019). 
Um estudo clínico randomizado realizado no Reino Unido, jovens com transtorno depressivo, avaliou a personalidade de adolescentes que se automutilam, notou-se que meninas apresentaram mais alto nível de neuroticismo do que os meninos em todos os grupos de frequência de automutilação. Por outro lado, os meninos apresentaram níveis mais elevados de psicoticismo, independentemente da experiência de automutilação. Tanto o neuroticismo quanto o psicoticismo se correlacionaram positivamente com a ocorrência de lesões autoprovocadas, o que significa que a personalidade das crianças pode desempenhar um papel importante na transição da automutilação episódica para a recorrente (Sayal et al., 2019).

Ao analisar o risco de automutilação em pessoas com epilepsia, um estudo de coorte de base populacional também foi identificada a maior probabilidade de automutilação entre pessoas com diagnóstico prévio de transtorno mental, sendo o aumento do risco proporcional ao número de encaminhamentos a serviços psiquiátricos. Percebeu-se um risco cinco vezes maior associado ao histórico de uso indevido de álcool e outras substâncias. Isso poderia contribuir para o aumento do risco de automutilação experimentado por esses indivíduos (Gorton et al., 2018).

A automutilação, em adolescentes, apresenta-se como um fator associado às tentativas de suicídio e, também, aos transtornos psiquiátricos, porém vale destacar que os problemas de saúde mental são mais graves em adolescentes que tentam suicídio do que naqueles que fazem automutilação (Liu et al., 2017).

Em estudos nacionais e internacionais, verificou-se que a maior prevalência é no sexo feminino como na Irlanda (53,7\%), Ásia (60\%), Noruega (70\%) e cidades portuguesas (78,94\%); em adolescentes portadoras de algum transtorno mental, dentre eles o depressivo $(73,77 \%)$, de humor $(10,47 \%)$ bipolaridade $(10,44 \%)$ e clinicamente deprimidas (50\%) (Victor et al., 2018).

Ao analisar o Manual Diagnóstico e Estatístico de Transtornos Mentais - DSM, quinta edição, este enquadra a automutilação no campo sintomas que podem se manifestar em diversos transtornos conhecidos, desde os Transtornos do Neurodesenvolvimento (APA, 2014, p. 78, 80), passando pelos Transtornos Dissociativos de Identidade (comportamento autolesivo predominante em mulheres, APA, 2014. p. 294, 299), até o Transtorno de Personalidade Borderline (APA, 2014, p. 664).

\subsection{Outros fatores associados}

Estudos transversais mostraram que entre estudantes a baixa frequência escolar, as conexões e as experiências escolares fracas e atitudes negativas em relação à escola foram associados a um risco aumentado de automutilação. Também há evidências de taxas mais altas de automutilação entre jovens adultos com histórico de mau desempenho escolar, mas um risco menor entre aqueles que frequentaram escolas com desempenho acadêmico médio inferior (Epstein et al., 2020).

Já entre estudantes universitários, percebe-se como fator influente na automutilação as mudanças neurobiológicas e psicológicas, o funcionamento intrapessoal e interpessoal, as relações familiares abusivas e violência no namoro. Destacou-se ainda que a ausência de apoio e orientação, tal como, conhecer alguém que pratica a automutilação, como fatores associados ao início desse comportamento (Kiekens et al., 2019).

Já entre presidiários, as associações mais fortes foram feitas ao confinamento solitário, violência ou perpetração de agressão, infrações disciplinares, vitimização sexual ou física, suporte social insuficiente, ameaças de violência, nenhum contato social ou visitas, não trabalhar na prisão e alojamento de célula única (Favril et al., 2020).

De uma forma geral, alguns comportamentos foram vistos como fator de risco em comportamentos autolesivos por poderem se apresentar associado a algum tipo de sofrimento psíquico. Dentre eles, problemas de sono, baixo índice de extroversão, vulnerabilidade neurobiológica, exclusão social, solidão, uso de drogas ilícitas, crenças sobre adversidade e comportamento problemático (Wang et al., 2020). Análises totalmente ajustadas mostraram uma associação positiva das 
taxas de lesões autoprovocadas com a porcentagem da população desempregada, famílias com aluguel privado, população com doença de longa duração limitada e famílias monoparentais (Lin et al., 2019).

Montini \& Stephan (2019) contribuem com esse pensamento ao afirmar que a automutilação pode ser percebida a partir de sinais como: um aumento de tensão, raiva de si mesmo, depressão, ansiedade, disforia (um mal estar psíquico acompanhado por sentimentos depressivos, tristeza, melancolia e pessimismo) e sensação de perda de controle. Podem ser diversos os fatores precipitantes: sensações de rejeição ou abandono (real ou imaginário), culpa e vazio, sentimento de inutilidade e sensação de irrealidade, em que os motivos para se automutilar se sobrepõem no mesmo indivíduo.

\section{Considerações Finais}

Os indivíduos que se envolvem em comportamentos autolesivos geralmente apresentam expectativas de buscar alívio de um sentimento negativo ou estado cognitivo para resolver uma dificuldade interpessoal e induzir um estado emocional positivo. Essa atitude demonstra um momento de sofrimento psíquico com tendência a se tornar repetitiva e, mesmo não tendo intenção primária suicida, possui repercussões negativas para a saúde e a vida.

Ao se tentar analisar, o que tem sido produzido sobre fatores determinantes da automutilação, na literatura científica nacional e internacional, percebe-se a complexidade da problemática e compreende-se que por ter origem multifatorial, necessita de intervenções intersetoriais, em rede que proporcionem um cuidar integral e equânime e clínica ampliada. No entanto, por se tratar de um de uma temática atual, ainda se tem uma limitação no aprofundamento das discussões e das possíveis intervenções.

Mediante os fatores de risco identificados, apontamos alguns possíveis fatores protetores: padrões de apego estáveis, familiares presentes, rede de apoio social, bom desempenho e funcionamento escolar e profissional, recursos financeiros suficientes, histórico cultural e religioso, boa gestão do tempo livre e apoio institucional.

Nesse estudo, podemos mencionar como pontos limitantes: o número reduzido de idiomas e bases de dados, além de terem sido utilizados apenas artigos disponíveis gratuitamente. Como lacunas do conhecimento podemos citar a ausência de artigos que associassem a automutilação aos fatores socioeconômicos e étnico e culturais.

Reitera-se a necessidade de prosseguir os estudos sobre o fenômeno para que se possa continuar qualificar e aprofundar a compreensão sobre causas, fatores e determinantes suas e contribuir com a construção de políticas públicas que previnam e promovam a prevenção das diversas formas de violência autoprovocada.

\section{Referências}

Almeida, R. S. (2018). A prática da automutilação na adolescência: o olhar da psicologia escolar/ educacional. Caderno de graduação - Ciências Humanas E Sociais - UNIT - ALAGOAS, 4(3), 147

American Psychiatric Association. (2014). DSM-5: manual diagnóstico e estatístico de transtornos mentais (5rd ed.)

Brown, R. C.; Fischer, T.; Goldwich, A. D.; \& Keller, F. (2017). Cutting: Non-suicidal self-injury (NSSI) on Instagram. Psychological Medicine.

Epstein, S.; Roberts, E.; Sedgwick, R.; Polling, C.; Finning, K.; Ford, T.; Dutta, R.; \& Downs, J. (2020). School absenteeism as a risk factor for self-harm and suicidal ideation in children and adolescents: a systematic review and meta-analysis. European Child and Adolescent Psychiatry, 29 (9), $1175-1194$.

Favril, L.; Yu, R.; Hawton, K.; \& Fazel, S. (2020). Risk factors for self-harm in prison: a systematic review and meta-analysis. The Lancet Psychiatry, 7 (8), $682-691$.

Galvão, C. M. (2006). Níveis de evidência. Acta Paulista de Enfermagem, 19 (2).

Gorodetsky, E.; Carli, V.; Sarchiapone, M.; Roy, A.; Goldman, D.; \& Enoch, M.-A. (2016). Predictors for self-directed aggression in Italian prisoners include externalizing behaviors, childhood trauma and the serotonin transporter gene polymorphism 5-HTTLPR. Genes, brain, and behavior, 15 (5), $465-473$.

Gorton, H. C.; Webb, R. T.; Pickrell, W. O.; Carr, M. J.; \& Ashcroft, D. M. (2018). Risk factors for self-harm in people with epilepsy. Journal of Neurology, 265 (12), 3009-3016. 
Khasawneh, A.; Madathil, K. C.; Dixon, E.; Wiśniewski, P.; Zinzow, H.; \& Roth, R. (2020). Examining the self-harm and suicide contagion effects of the blue whale challenge on YouTube and Twitter: Qualitative study. JMIR Mental Health, 7 (6).

Kiekens, G.; Hasking, P.; Claes, L.; Boyes, M.; Mortier, P.; Auerbach, R. P.; Cuijpers, P.; Demyttenaere, K.; Green, J. G.; Kessler, R. C.; Myin-Germeys, I.; Nock, M. K.; \& Bruffaerts, R. (2019). Predicting the incidence of non-suicidal self-injury in college students. European Psychiatry, 59, 44-51.

Law, B. M. F.; \& Shek, D. T. L. (2016). A 6-year Longitudinal Study of Self-harm and Suicidal Behaviors among Chinese Adolescents in Hong Kong. Journal of Pediatric and Adolescent Gynecology, 29 (1), S38-S48.

Lin, C.-Y.; Bickley, H.; Clements, C.; Webb, R.; Gunnell, D.; Hsu, C.-Y.; Shu-Sen Chang, S.-S.; \& Kapur, N. (2019). Spatial patterning and correlates of selfharm in Manchester, England. Epidemiology and psychiatric sciences, 29, e72.

Liu, Y.; Zhang, J.; \& Sun, L. (2017). Who are likely to attempt suicide again? A comparative study between the first and multiple timers. Comprehensive Psychiatry, 78, 54-60.

Lockwood, C.; Porrit, K.; Munn, Z.; Rittenmeyer, L.; Salmond, S.; Bjerrum, M.; Loveday, H.; Carrier, J.; \& Stannard, D. (2020). Chapter 2: Systematic reviews of qualitative evidence. In E. Aromataris, Z Munn Eds), JBI Manual for Evidence Synthesis.

Lung, F. W.; Shu, B.-C.; Chiang, T.-L.; \& Lin, S.-J. (2020). Relationships between internet use, deliberate self-harm, and happiness in adolescents: A Taiwan birth cohort pilot study. PLoS ONE, 15 (7), 1-13.

Montini, L. S.; \& Stephan, F. (2019). A prática da automutilação na adolescência. Caderno Científico Fagoc de Graduação e Pós-Graduação, 4, 67-76.

Moraes, D. X.; Moreira, É. S.; Sousa, J. M.; Vale, R. R. M.; Pinho, E. S.; Dias, P. C. S.; \& Caixeta, C. (2020). "Caneta é a lâmina, minha pele o papel”: fatores de risco da automutilação em adolescentes. Revista Brasileira de Enfermagem, 73 (Suppl 1), 1-9.

Moreira, É. S.; Vale, R. R. M.; Caixeta, C. C.; \& Teixeira, R. A. G. (2020). Automutilação em adolescentes: revisão integrativa da literatura. Ciência \& Saúde Coletiva, 25 (10), 3945-3954.

Olfson, M.; Wall, M.; Wang, S.; Crystal, S.; Bridge, J. A.; Liu, S.-M.; \& Blanco, C. (2018). Suicide after deliberate self-harm in adolescents and young adults. Pediatrics, 141 (4).

Peh, C. X.; Shahwan, S.; Fauziana, R.; Mahesh, M. V.; Sambasivam, R.; Zhang, Y.; Ong, S. H.; Chong, S. A.; \& Subramaniam, M. (2017). Emotion dysregulation as a mechanism linking child maltreatment exposure and self-harm behaviors in adolescents. Child Abuse and Neglect, 67 (April), $383-390$.

Richmond-Rakerd, L. S.; Caspi, A.; Arseneault, L.; Baldwin, J. R.; Danese, A.; Houts, R. M.; Matthews, T.; Wertz, J.; \& Moffitt, T. E. (2019). Adolescents Who Self-Harm and Commit Violent Crime: Testing Early-Life Predictors of Dual Harm in a Longitudinal Cohort Study. The American journal of psychiatry, $176(3), 186-195$.

Ronzitti, S.; Loree, A. M.; Potenza, M. N.; Decker, S. E.; Wilson, S. M.; Abel, E. A.; Haskell, S. G.; Brandt, C. A.; \& Goulet, J. L. (2019). Gender Differences in Suicide and Self-Directed Violence Risk Among Veterans With Post-traumatic Stress and Substance Use Disorders. Women's Health Issues, 29 , S94-S102.

Sayal, K.; Roe, J.; Ball, H.; Atha, C.; Kaylor-Hughes, C.; Guo, B.; Townsend, E.; \& Morriss, R. (2019). Feasibility of a randomised controlled trial of remotely delivered problem-solving cognitive behaviour therapy versus usual care for young people with depression and repeat self-harm: Lessons learnt (eDASH). BMC Psychiatry, 19 (1), 1-12.

Silva, A. C.; \& Botti, N. C. L. (2018). Uma investigação sobre automutilação em um grupo da rede social virtual Facebook. SMAD. Revista eletrônica saúde mental álcool e drogas, 14 (4), 203-210.

Souza, M. T.; Silva, M. D.; \& Carvalho, R. (2010). Revisão integrativa: o que é e como fazer. Einstein, 8 (1), $102-106$.

Victor, S. E.; Muehlenkamp, J. J.; Hayes, N. A.; Lengel, G. J.; Styer, D. M.; \& Washburn, J. J. (2018). Characterizing gender diferences in nonsuicidal selfinjury: evidence from a large clinical sample of adolescentes and adults. Comprehensive Psychiatry, 82, 53-60.

Wang, H.; Wang, Q.; Liu, X.; Gao, Y.; \& Chen, Z. (2020). Prospective interpersonal and intrapersonal predictors of initiation and cessation of non-suicidal self-injury among chinese adolescents. International Journal of Environmental Research and Public Health, 17 (24), 1-13.

World Health Organization [homepage on the Internet]. Geneva: World Health Organization. Closing the gap: policy into practice on social determinants of health: discussion $2011 . \quad$ paper 2 https://www.who.int/sdhconference/Discussion-Paper-EN.pdf » https://www.who.int/sdhconference/Discussion-Paper-EN.pdf. 